\title{
Pengukuran Coverage Outdoor Wireless $L A N$ dengan Metode Visualisasi Di Universitas Islam Negeri Sunan Gunung Djati Bandung
}

\author{
Eki Ahmad Zaki Hamidi, Nanang Ismail, Ramadhan Syahyadin \\ Jurusan Teknik Elektro Fakultas Sains dan Teknologi \\ Universitas Islam Negeri Sunan Gunung Djati Bandung \\ Jl. AH. Nasution No. 105 Bandung \\ ekiahmadzaki@uinsgd.ac.id, nanang.is@uinsgd.ac.id, elektro.sgd@gmail.com
}

\begin{abstract}
Abstrak - Universitas Islam Negeri Sunan Gunung Djati Bandung merupakan salah satu instansi pendidikan yang memanfaatkan wireless LAN sebagai media pembelajaran dan informasi, namun banyaknya penggunaan frekuensi dan channel pada wireless LAN dapat menyebabkan overlap hingga terjadi interferensi sinyal. Agar mendapatkan coverage jaringan yang baik pada perangkat outdoor wireless LAN, diperlukan suatu perencanaan dalam penempatan posisi antena dan perhitungan Link Budget yang terdiri dari free space loss, effective isotropically radiated power, received signal level dan system operating margin. Selain itu perhitungan dilakukan secara simulasi dengan menggunakan software Radio Mobile untuk melihat hasil coverage area secara visual. Pengukuran jaringan yang dilakukan terdiri dari 1 antena Server dan 3 access point yang ditempatkan pada posisi yang telah ditentukan berdasarkan kondisi eksisting. Hasil rancangan jaringan yang dianalisis menggunakan perhitungan Link Budget secara teori maupun simulasi dengan nilai parameter System Operating Margin (SOM) terbesar pada server sebesar 47,26 dB, sedangkan pada access point\#1 46,26 dB, access point\#2 45,76 dB dan access point\#3 39,5 dB dimana telah memenuhi batas perancangan sinyal yang baik.
\end{abstract}

Kata kunci: Outdoor Wireless LAN, Coverage, Link Budget, Visualisasi, System Operating Margin

\section{Pendahuluan}

Jaringan Lokal tanpa kabel atau yang sering disebut dengan Wireless LAN adalah suatu jaringan area lokal tanpa kabel dimana media transmisinya menggunakan frekuensi radio (RF) dan infrared (IR), untuk memberi sebuah koneksi jaringan ke seluruh pengguna dalam area disekitar. Jaringan Wireless LAN dapat dimanfaatkan sebagai media untuk menunjang pembelajaran dilihat dari beberapa keunggulannya. Dengan membangun jaringan WLAN di instansi pendidikan seperti Sekolah dan Universitas dapat memudahkan pelajar dalam mencari informasi untuk bahan pembelajaran di kelasnya masing-masing. Meskipun hal tersebut sudah dapat diimplementasikan akan tetapi, masih banyak prosedur proses penempatan posisi jaringan Wireless LAN yang kurang diperhatikan dengan benar, terutama penempatan diluar bangunan (Outdoor). Hal tersebut dapat berpengaruh pada kualitas jaringan yang dihasilkan [2].

Universitas Islam Negeri Sunan Gunung Djati Bandung yang merupakan salah satu instansi pendidikan, telah memanfaatkan jaringan WLAN sebagai sarana dalam menunjang media pembelajaran mahasiswa. Namun banyaknya akses jaringan wireless yang terdapat di area kampus UIN Sunan Gunung Djati Bandung dapat mempengaruhi kualitas jaringan, penumpukan sinyal RF yang disebabkan oleh banyaknya sinyal radio yang dipancarkan pada frekuensi dan channel yang sama akan mengakibatkan interferensi sinyal [5].

TELKA, Vol.2, No.2, November 2016, pp. 82 93

ISSN (e): 2540-9123

ISSN (p): 2502-1982 
Oleh karena itu pada penelitian kali ini akan dibuat suatu perencanaan dalam pembangunaan jaringan Wireless Local Area Network (WLAN) di area luar (outdoor) UIN Sunan Gunung Djati Bandung. Perancangan dilakukan dengan menggunakan metode visualisasi, sehingga hasil akhir yang didapat berupa tampilan cakupan jaringan wireless LAN yang sudah dioptimasi. Visualiasi cakupan jaringan dibuat dengan menggunakan software Radio Mobile, selain memuat tampilan cakupan jaringan dan blank spot area pada aplikasi tersebut juga memuat parameter Link Budget yang terdiri dari nilai free space loss (FSL), nilai Effective Isotropically Radiated Power (EIRP), Received Signal Level (RSL) dan nilai System Operating Margin (SOM). Nilai perhitungan berdasarkan simulasi tersebut dibandingkan dengan perhitungan Link Budget secara teori dalam kondisi pada propagasi Line of Sight, dengan tujuan untuk menentukan rancangan jaringan yang akan disimulasikan sesuai dengan perhitungan secara teori.

\section{Landasan Teori}

\subsection{Wireless LAN}

Jaringan lokal tanpa kabel atau WLAN adalah suatu jaringan area lokal tanpa kabel dimana media transmisinya menggunakan frekuensi radio (RF) dan infrared (IR), untuk memberi sebuah koneksi jaringan ke seluruh pengguna dalam area disekitarnya. WLAN menggunakan teknologi frekuensi radio sebagai media penyimpanan data dan memiliki berbagai kemudahan bagi pengguna penerapannya[1]. WLAN memiliki beberapa komponen dalam arsitektur jaringannya yaitu access point dan wireless station/client. Federal Communications Commission (FCC) mengatur penggunaan alat dari wireless LAN yang terdiri dari beberapa standarisasi pada tabel dibawah:

Tabel 1. Standarisasi Wireless LAN [1]

\begin{tabular}{|c|c|c|c|}
\hline Spesifikasi & Kecepatan & $\begin{array}{c}\text { Frekuensi } \\
\text { Band }\end{array}$ & $\begin{array}{c}\text { Cocok } \\
\text { dengan }\end{array}$ \\
\hline $802.11 \mathrm{~b}$ & $11 \mathrm{Mb} / \mathrm{s}$ & $\sim 2.4 \mathrm{GHz}$ & $\mathrm{b}$ \\
\hline $802.11 \mathrm{a}$ & $54 \mathrm{Mb} / \mathrm{s}$ & $\sim 5 \mathrm{GHz}$ & $\mathrm{a}$ \\
\hline $802.11 \mathrm{~g}$ & $54 \mathrm{Mb} / \mathrm{s}$ & $\sim 2.4 \mathrm{GHz}$ & $\mathrm{b}, \mathrm{g}$ \\
\hline $802.11 \mathrm{n}$ & $100 \mathrm{Mb} / \mathrm{s}$ & $\sim 2.4 \mathrm{GHz}$ & $\mathrm{b}, \mathrm{g}, \mathrm{n}$ \\
\hline
\end{tabular}

\subsection{Frekuensi Radio (RF)}

Frekuensi Radio adalah sinyal arus berfrekuensi tinggi yang berubah-ubah yang melewati konduktor tembaga yang panjang dan kemudian diradiasikan ke udara melalui sebuah antenna[1]. Sinyal RF memiliki beberapa sifat dan parameter dalam prinsip kerjanya yang merambat diudara, diantaranya yaitu:

\section{Gain}

Merupakan besarnya tingkat penguatan pada sinyal RF pada saat proses pengiriman dan penerimaan. merupakan besarnya tingkat penguatan pada sinyal RF pada saat proses pengiriman dan penerimaan[9].

2. Power Loss

Merupakan suatu tingkat dalam penurunan / kerusakan sinyal yang disebabkan oleh beberapa faktor, seperti resistansi dari kabel dan konektor menyebabkan kerusakan karena perubahan sinyal AC terlalu panas dan Impedance yang tidak seimbang pada kabel dan konektor dapat mengakibatkan power direfleksikan kembali ke sumber, yang mana dapat menyebabkan degradasi sinyal[2].

3. Interferensi

Ada beberapa jenis interferensi radio yang dapat muncul selama pemasangan WLAN. Diantaranya interferensi narrowband, interferensi all-band, interferensi akibat pemakaian channel yang sama atau channel yang bersebelahan[1]. 


\subsection{Antena Wireless Outdoor}

Antenna merupakan perangkat elektronik yang berperan sebagai media transmisi nirkabel/wireless yang memanfaatkan udara/ruang bebas sebagai media penghantar. Terdapat beberapa jenis antenna yang biasa digunakan pada jaringan wireless, jenis-jenis antenna tersebut akan dijelaskan sesuai dengan bentuk dan cara kerja nya sesuai dengan jenis antenna yang digunakan pada penelitian ini[6].

1. Antena Omnidirectional

Antenna omni meradiasikan sinyal ke segala arah dengan polarisasi pancarnya kearah horizontal, akan tetapi menunjukan adanya direktivitas dalam arah vertikal, dengan mengonsentrasikan energinya ke dalam bentuk kue donat. Bentuk fisik antenna omni dapat dilihat pada gambar dibawah.

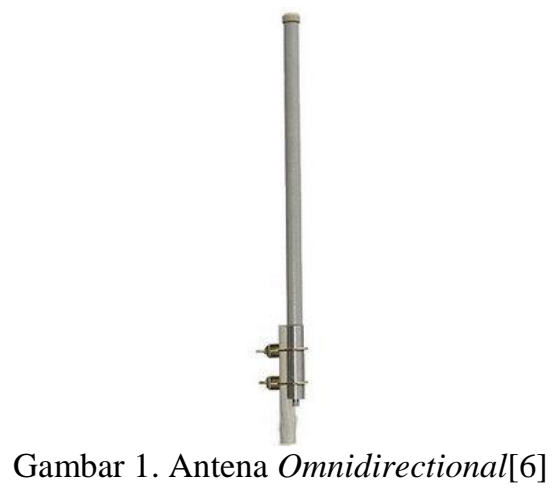

2. Antena Sectoral

Antenna sectoral umum nya memiliki penguatan (Gain) yang lebih tinggi dari antenna omni sekitar 10-19 dBi. Sangat baik untuk memberikan cakupan jaringan didaerah dalam jarak 6-8 $\mathrm{km}$. Bila pada antenna omni radiasi sinyal dipancarkan ke segala arah maka pada antenna sectoral pancaran radiasi sinyal dibatasi berdasarkan spesifikasi nya masing-masing, namun yang sering digunakan radiasi pancaran sebesar $60^{\circ}, 90^{\circ}$, dan $120^{\circ}$. Bentuk fisik antenna sectoral dapat dilihat pada gambar dibawah.

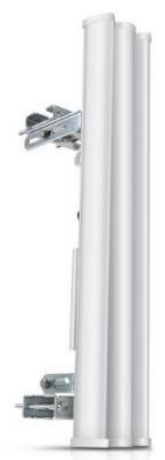

Gambar 2. Antena Sectoral[6]

\subsection{Link Budget}

Link budget merupakan sebuah cara untuk menghitung mengenai semua parameter dalam transmisi sinyal, mulai dari gain dan losses dari Tx sampai Rx melalui media transmisi. Untuk menentukan kualitas daya pancar maupun daya terima pada jaringan wireless LAN, maka digunakan perhitungan Link Budget pada jaringan wireless. Adapun parameter-parameter yang berhubungan dengan Link Budget dalam merancang jaringan outdoor wireless terdiri dari[4].

1. Free Space Loss

FSL merupakan model propagasi yang digunakan dengan mengkondisikan transmitter dan receiver berada pada lingkungan tanpa bangunan ataupun halangan lain yang dapat 
menimbulkan difraksi, refraksi, antenna maupun blocking. Besar redaman ruang bebas secara matematis dapat dihitung dengan menggunakan persamaan[6]:

Lfs $\quad=32,45+20 \log d+20 \log f$

Keterangan:

Lfs $=$ Free space loss $(\mathrm{dB})$

$\mathrm{d}=$ Jarak antara transmitter dan receiver $(\mathrm{Km})$

$\mathrm{f}=$ Frekuensi $(\mathrm{MHz})$

\section{Effective Isotropically Radiated Power}

Merupakan total energy yang dikeluarkan oleh sebuah antenna maupun access point. Pada saat sebuah access point mengirim energinya ke antenna untuk dipancarkan, pengurangan besar energy akan terjadi didalam kabel, secara matematis dinyatakan pada persamaan berikut[4]:

EIRP $=$ PTx - LTx + GTx

Keterangan:

$\mathrm{EIRP}=$ Effective Isotropic Radiated Power $(\mathrm{dBm})$

PTx = Daya pancar antenna pemancar

LTx $=$ Loss kabel (cable loss) di antenna pemancar

\section{Received Signal level}

Merupakan suatu tingkat sinyal yang diterima di perangkat penerima dan nilainya harus lebih besar dari sensitivitas perangkat penerima (Received Sensitivity). Agar nilai RSL dapat lebih besar dari received Signal, diperlukan pemilihan yang tepat. Jika received Signal lebih kecil nilainya dari sensitivitas penerima maka sinyal yang dipancarkan tidak dapat diterima dengan baik oleh perangkat penerima. Adapun persamaan RSL adalah sebagai berikut:

$\mathrm{RSL}=\mathrm{EIRP}-\mathrm{FSL}+\mathrm{GRx}-\mathrm{LRx}$

Keterangan:

$\mathrm{EIRP}=$ Effective Isotropic Radiated Power $(\mathrm{dBm})$

$\mathrm{RSL}=$ Reicived Level Signal $(\mathrm{dBm})$

$\mathrm{FSL}=$ Free Space Loss $(\mathrm{dB})$

$\mathrm{GTx}=$ Gain Antenna sisi pengirim $(\mathrm{dB})$

LRx $=$ Redaman saluran transmisi $(\mathrm{dB})$

\section{System Operating Margin}

Merupakan salah satu parameter pada perhitungan Link Budget yang paling penting, karena yang akan menentukan sinyal tersebut dapat diakses ataupun tidak. Untuk mengalahkan efek fading dan menghasilkan koneksi jaringan yang baik, setiap link gelombang mikro membutuhkan ekstra sinyal diatas minimum threshold receiver yang disebut juga dengan SOM. ada pun rumus perhitungannya sebagai berikut[4]:

SOM $=$ RSL - Rx Sensitivity

Keterangan:

RSL = Received Signal Level

Rx Sensitivity $=$ Sensitivitas antenna penerima

ISSN (e): 2540-9123

ISSN (p): 2502-1982 


\subsection{Software Radio Mobile}

Software Radio Mobile merupakan salah satu aplikasi simulator propagasi yang disediakan gratis. Software ini Dilengkapi dengan peta digital dan Geographical Information System (GIS) sehingga memungkinkan untuk melihat kontur tanah yang sesungguhnya dan SRTM (Space Shuttle Radar Terrain Mapping Mission) merupakan sebuah aplikasi yang berfungsi untuk mendapatkan peta digital dengan ketinggiannya. Sering digunakan untuk merancang sistem komunikasi radio terutama untuk VHF (Very High Frequency) atau UHF (Ultra High Frequency) maupun untuk frekuensi $2.4 \mathrm{GHz}, 3.3 \mathrm{GHz}, 5.8 \mathrm{GHz}$ atau lebih. Software ini beroperasi pada frekuensi $20 \mathrm{MHz}$ sampai $50 \mathrm{GHz}[3]$.

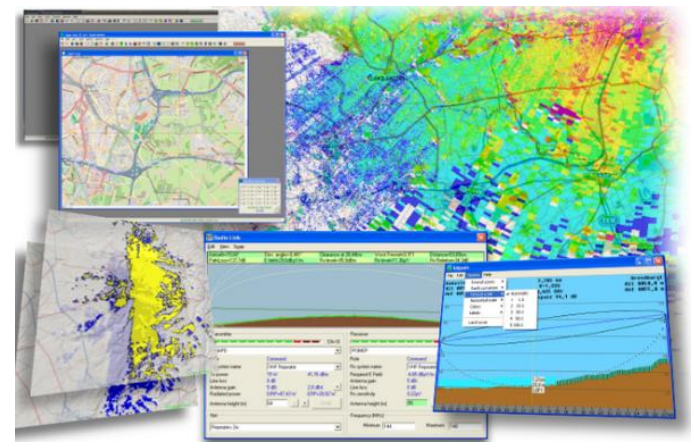

Gambar 3. Tampilan Radio Mobile[7]

\section{Perancangan Penelitian}

Perancangan penelitian yang akan digunakan dalam penelitian ini diantaranya yaitu pengumpulan data dengan metode studi literatur dan observasi, kemudian tahap berikutnya identifikasi masalah hingga melakukan percobaan dengan menggunakan metode visualiasi untuk mendapatkan data yang dianalisis hingga mendapatkan suatu kesimpulan. Adapun tahapan dari proses penelitian ini dijabarkan pada diagram alir dibawah:

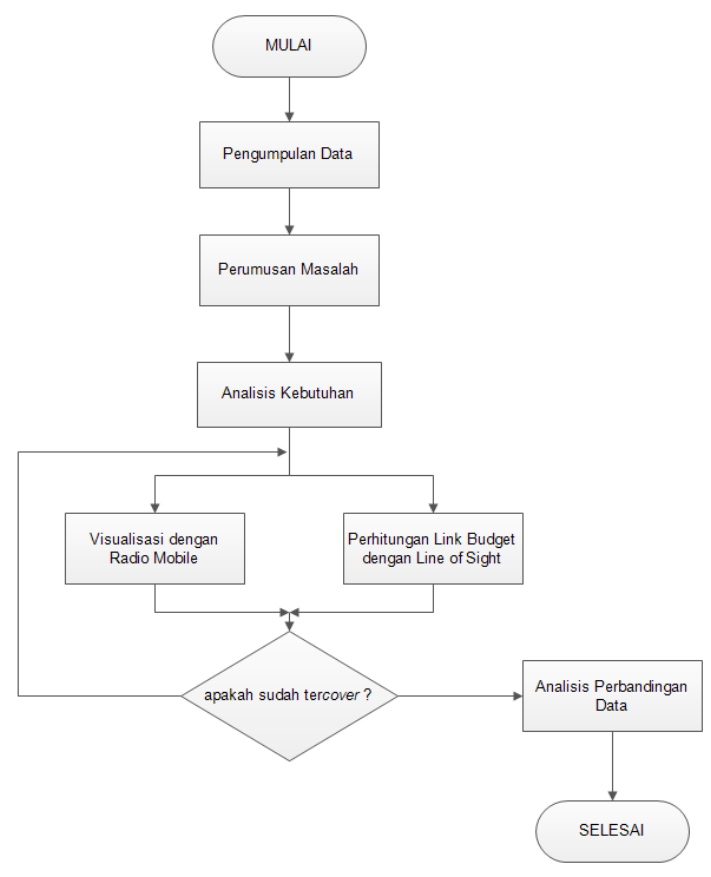

Gambar 4. Diagram Alir Metodologi Penelitian 


\subsection{Analisis Kebutuhan}

Adapun data yang dibutuhkan yaitu:

1. Denah dan Titik koordinat obyek penelitian.

UIN Sunan Gunung Djati bandung merupakan sebuah instansi pendidikan yang beralamat di Jalan A. Haji Nasution No. 105, Bandung, Jawa Barat 40614, yang berada pada titik koordinat $6^{\circ} 55^{\prime} 53^{\prime \prime S} 107^{\circ} 43^{\prime} 2^{\prime \prime E}$. Berikut adalah denah kampus UIN Sunan Gunung Djati Bandung beserta keterangan tiap - tiap bangunan:

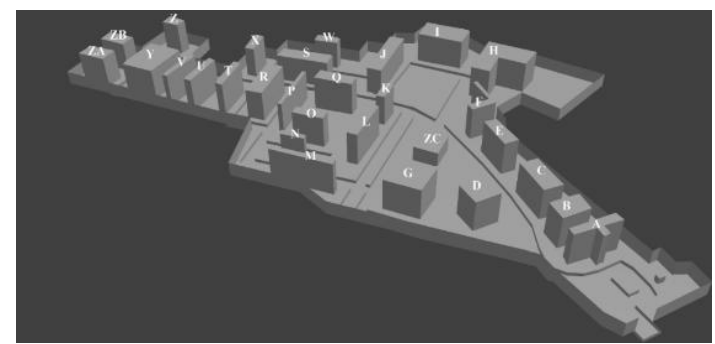

Gambar 5. Denah UIN Bandung

2. Spesifikasi Perangkat Jaringan (antenna / access point).

Pada penelitian perancangan simulasi jaringan wireless LAN ini akan dijabarkan spesifikasi dan parameter dari jenis dan perangkat wireless yang akan digunakan terdapat pada tabel dibawah:

Tabel 2. Nilai Spesifikasi Antena

\begin{tabular}{|c|c|c|}
\hline \multirow{2}{*}{ Parameter } & \multicolumn{2}{|c|}{ Nilai Spesifikasi } \\
\cline { 2 - 3 } & Sectoral & Omnidirectional \\
\hline Transmit Power & $21 \mathrm{dBm}$ & $20 \mathrm{dBm}$ \\
\hline Gain & $15 \mathrm{dBi}$ & $12 \mathrm{dBi}$ \\
\hline Frekuensi & $2400 \mathrm{MHz}$ & $2400 \mathrm{MHz}$ \\
\hline Rx Sensitivity & $-85 \mathrm{dBm}$ & $-85 \mathrm{dBm}$ \\
\hline Sudut Pancar & $120^{\circ}$ & $360^{\circ}$ \\
\hline
\end{tabular}

\subsection{Simulasi Radio Mobile}

Hasil perhitungan antara Server sebagai antenna Tx dengan Access point\#1 sebagai antenna Rx, didapat parameter nilai Link Budget sebagai berikut:

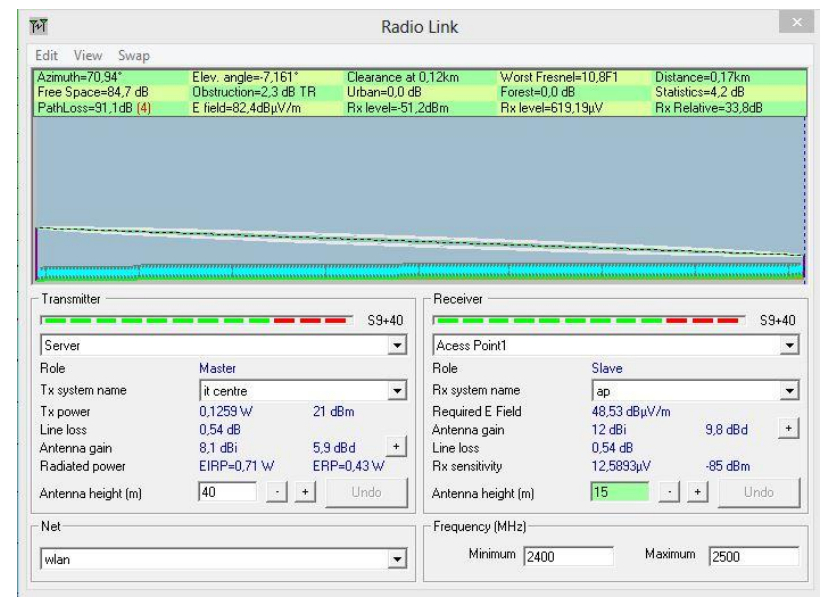

Gambar 6. Simulasi Tx Server ke Rx Ap\#1 
Hasil perhitungan antara Server sebagai antenna Tx dengan Access point\#2 sebagai antenna $\mathrm{Rx}$, didapat parameter nilai Link Budget sebagai berikut:

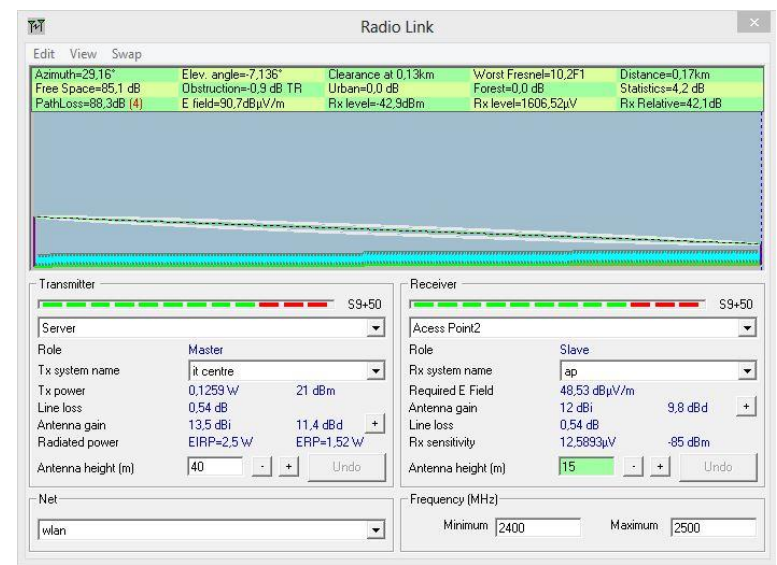

Gambar 7. Simulasi Tx Server ke Rx Ap\#2

Pada hasil perhitungan antara Server sebagai antenna Tx dengan Access point\#3 sebagai antenna Rx, didapat parameter nilai Link Budget sebagai berikut:

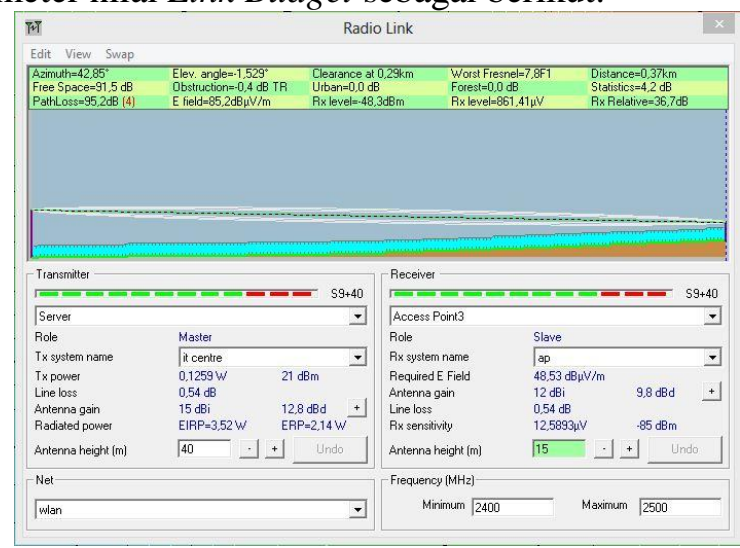

Gambar 8. Simulasi Tx Server ke Rx Ap\#3

Pada hasil perhitungan antara Access point\#1 sebagai antenna Tx dengan Server sebagai antenna Rx, didapat parameter nilai Link Budget sebagai berikut:

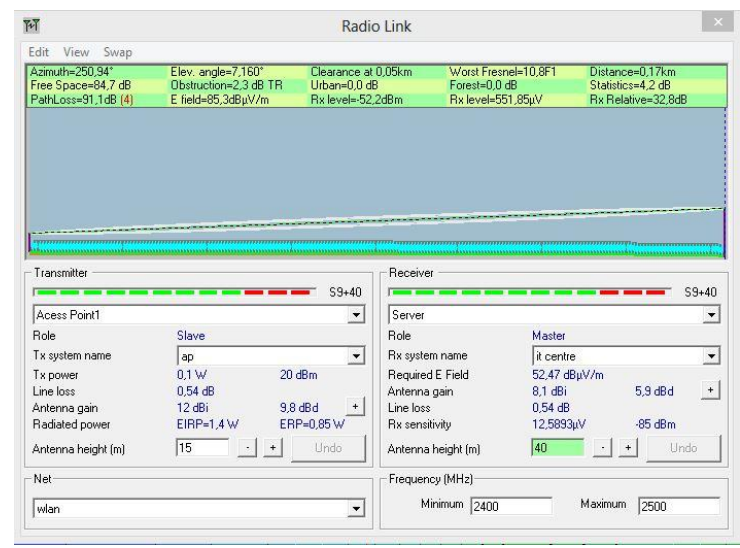

Gambar 9. Simulasi Tx Ap\#1 ke Rx Server 
Pada hasil perhitungan antara Access point\#2 sebagai antenna Tx dengan Server sebagai antenna Rx, didapat parameter nilai Link Budget sebagai berikut:

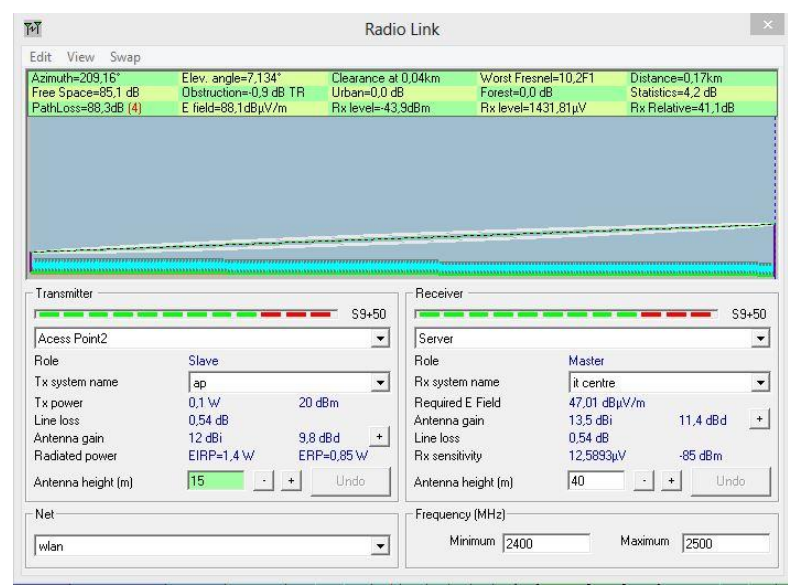

Gambar 10. Simulasi Tx Ap\#2 ke Rx Server

Pada hasil perhitungan antara Access point\#3 sebagai antenna Tx dengan Server sebagai antenna Rx, didapat parameter nilai Link Budget sebagai berikut:

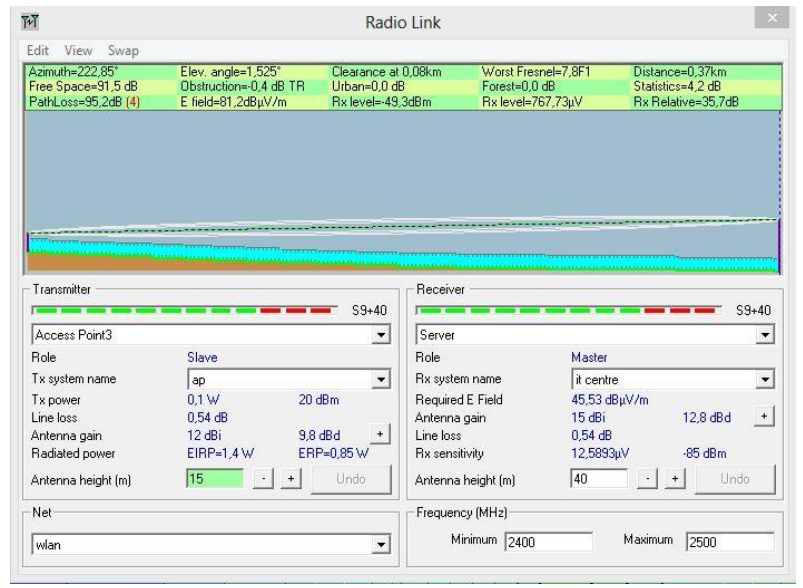

Gambar 11. Simulasi Tx Ap\#3 ke Rx Server

\section{Hasil dan Analisis}

\subsection{Perbandingan Link Budget}

Hasil perhitungan Link Budget baik secara teori maupun dengan simulasi yang telah didapatkan kemudian dibandingkan untuk mengetahui perbedaan nilai yang dihasilkan berdasarkan dari parameter jaringan yang telah ditentukan. Adapun parameter perhitungan Link Budget yang dibandingkan adalah sebagai berikut: 
1. Free Space Loss

Tabel 3. Perbandingan Nilai FSL

\begin{tabular}{|c|c|c|}
\hline Jarak (km) & FSL (Perhitungan) dB & FSL (Simulasi) dB \\
\hline 0,17 & 84,66 & 84,7 \\
\hline 0,18 & 85,16 & 85,1 \\
\hline 0,37 & 91,42 & 91,5 \\
\hline
\end{tabular}

Perbedaan yang dihasilkan dari kedua perhitungan disebabkan oleh perhitungan yang dihasilkan simulasi disertai dengan kontur tanah yang terdapat diseluruh area kampus UIN Sunan Gunung Djati Bandung serta hasil perhitungan pada simulasi yang hanya satu bilangan dibelakang koma sedangkan pada teori terdapat dua bilangan dibelakang koma.

\section{Effective Isotropically Radiated Power}

Tabel 4. Perhitungan Nilai EIRP

\begin{tabular}{|c|c|c|}
\hline Pancaran Antenna & $\begin{array}{c}\text { EIRP } \\
\text { (Perhitungan) } \\
\text { dBm }\end{array}$ & EIRP (Simulasi) dBm \\
\hline Server ke Access Point\#1 & 35,46 & 28,56 \\
\hline Server ke Access Point\#2 & 35,46 & 33,96 \\
\hline Server ke Access Point\#3 & 35,46 & 35,46 \\
\hline $\begin{array}{c}\text { Access Point\#1, Access } \\
\text { Point\#2, Access Point\#3 }\end{array}$ & 31,46 & 31,46 \\
\hline
\end{tabular}

Berdasarkan data perbandingan perhitungan Effective Isotropically Radiated Power dapat dilihat terdapat perbedaan nilai hasil perhitungan baik secara teori maupun simulasi, hal tersebut disebabkan karena pada perhitungan EIRP secara simulasi menghasilkan nilai gain pada antenna sectoral yang terhubung dengan access point\#1 dan access point\#2 berbeda sedangkan pada access point\#3 nilainya sesuai dengan yang telah ditentukan. Adapun untuk nilai EIRP terbesar ada pada antenna Server dengan nilai sebesar 35,46 dBm dan nilai tersebut masih dibawah batas penggunaan nilai EIRP maksimal.

3. Received Signal Level

Tabel 5. Perbandingan Nilai RSL

\begin{tabular}{|c|c|c|}
\hline Receive Sensitivity (dBm) & RSL (Teori) dBm & RSL (Simulasi) dBm \\
\hline Tx Server Rx Access Point\#1 & $-37,74$ & $-51,2$ \\
\hline Tx Server Rx Access Point\#2 & $-38,24$ & $-42,9$ \\
\hline Tx Server Rx Access Point\#3 & $-44,5$ & $-48,3$ \\
\hline Tx Acess Point\#1 Rx Server & $-31,46$ & $-52,2$ \\
\hline Tx Acess Point\#2 Rx Server & $-39,24$ & $-43,9$ \\
\hline Tx Acess Point\#3 Rx Server & $-45,5$ & $-49,3$ \\
\hline
\end{tabular}


Berdasarkan data perbandingan perhitungan Received Signal Level dapat dilihat terdapat beberapa perbedaan nilai yang dihasilkan. Perbedaan nilai terdapat di seluruh hasil perhitungan baik secara teori maupun secara simulasi. Perbedaan hasil tersebut disebabkan karena penggunaan nilai FSL dengan nilai EIRP mengalami perbedaan nilai, sehingga hasil perhitungan pada Received Signal Level tentunya akan mengalami perbedaan nilai pula.

\section{System Operating Margin}

Tabel 6. Perbandingan Nilai SOM

\begin{tabular}{|c|c|c|}
\hline Pancaran Antenna & $\begin{array}{c}\text { SOM } \\
\text { (Perhitungan) dB }\end{array}$ & $\begin{array}{c}\text { SOM } \\
\text { (Simulasi) } \\
\text { dB }\end{array}$ \\
\hline Server ke Access Point\#1 & 47,26 & 33,8 \\
\hline Server ke Access Point\#2 & 46,76 & 42,1 \\
\hline Server ke Access Point\#3 & 40,5 & 36,7 \\
\hline Access Point\#1 ke Server & 46,26 & 32,8 \\
\hline Access Point\#2 ke Server & 45,76 & 41,1 \\
\hline Access Point\#3 ke Server & 39,5 & 31,3 \\
\hline
\end{tabular}

Perbedaan nilai terdapat di seluruh hasil perhitungan baik secara teori maupun secara simulasi. Perbedaan hasil tersebut disebabkan karena penggunaan nilai RSL mengalami perbedaan nilai, sehingga hasil perhitungan pada System Operating Margin tentunya akan mengalami perbedaan nilai pula. Berdasarkan data perbandingan perhitungan System Operating Margin baik pada perhitungan teori maupun simulasi nilai SOM berada diatas $20 \mathrm{~dB}$ yang berarti kualitas perancangan sinyal sudah baik.

\subsection{Visualisasi Coverage Jaringan}

Pada tampilan coverage di software Radio Mobile terdapat beberapa symbol dan warna yang memiliki fungsinya masing-masing berdasarkan dari rancangan yang telah dibangun dan obyek penelitian. Pada coverage area yang telah ditampilkan, akan terlihat dengan penyebaran warna merah yang berasal dari antenna server maupun ketiga access point.

Berdasarkan analisis coverage sebelumnya sudah dapat diketahui bahwa pada antenna server jarak radius coverage sejauh 0,42 km dengan arah pancar menghadap ke access point\#3, sedangkan pada ketiga access point memiliki jarak radius coverage sejauh $0,12 \mathrm{~km}$. Adapun format tampilan coverage keseluruhan antenna yang ditampilkan di Google Earth sehingga wilayah obyek penelitian dapat terlihat jelas dengan coverage area yang dihasilkan:

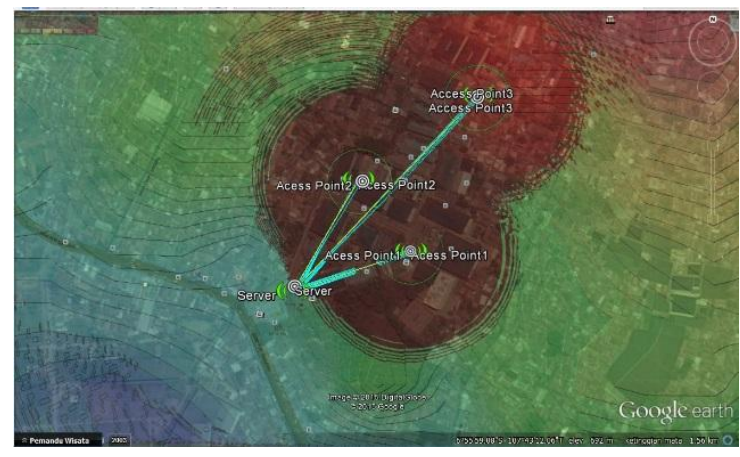

Gambar 12. Hasil Coverage Seluruh Antena 
Berdasarkan tampilan coverage area pada antenna server diatas dapat dilihat terdapat beberapa area luar bangunan yang ter-cover jaringan wireless LAN yang dihasilkan dari seluruh antenna yang terhubung dengan jaringan outdoor wireless LAN hampir memenuhi seluruh area kampus UIN Sunan Gunung Djati Bandung, hanya terdapat satu area terbuka strategis yang tidak ter-cover yaitu pada area taman Rektorat.

\section{Kesimpulan dan Saran \\ 5.1. Kesimpulan}

Berdasarkan hasil pengolahan data, perhitungan secara teori maupun secara simulasi serta hasil analisis Link Budget pada perencanaan Outdoor Wireless LAN di kampus UIN Sunan Gunung Djati Bandung dapat ditarik kesimpulan sebagai berikut:

1. Hasil visualisasi jaringan wireless LAN dengan coverage area pada kondisi LOS yang ditampilkan mencapai radius pancaran dari server sebesar $0,43 \mathrm{~km}$ sedangkan dari access point\#1, access point 2 dan access point $\# 3$ sebesar $0,12 \mathrm{~km}$.

2. Perhitungan Link Budget dalam kondisi LOS menunjukan beberapa hasil yang terdiri dari:

- Semakin jauh jarak antar antenna pengirim (Tx) dengan antenna penerima (Rx) maka nilai FSL semakin besar.

- Nilai EIRP pada seluruh antenna sudah memenuhi batas nilai pemakaian pada frekuensi $2,4 \mathrm{GHz}$ baik pada ketiga access point maupun pada server.

- Nilai RSL baik pada antenna server maupun pada ketiga access point lebih besar dari nilai $R x$ Sensitivity nya.

- Nilai SOM baik pada server maupun ketiga access point telah melebihi batas perancangan sinyal sebesar $20 \mathrm{~dB}$.

3. Hasil perhitungan pada simulasi Radio Mobile dengan perhitungan teori sebagian besar berbeda, karena pada simulasi mem- pertimbangkan nilai kontur tanah dan arah antenna yang akan mempengaruhi pola pancar sinyal, sedangkan pada teori hanya memuat perhitungan dengan rumus yang telah ditentukan secara matematis.

\subsection{Saran}

Saran-saran yang dapat diberikan dengan harapan penelitian tersebut dapat ditingkatkan kualitasnya terdiri dari:

1. Penggunaan software simulasi yang memperhitungkan efek multipath agar hasil analisis dari perencanaan outdoor wireless ini benar-benar nyata sesuai dengan keadaan pada area yang akan dibangun jaringan wireless.

2. Perlu dilakukannya peninjauan kapasitas akses jaringan outdoor wireless pada pengguna jaringan agar dapat diketahui kualitas akses jaringan yang telah dirancang dapat memenuhi kebutuhan akses internet.

\section{Daftar Pustaka}

[1] Budi Catur. 2014. "Analisa Performasi dan Coverage Wireless Local Area Network 802.11B/G/N Pada Pemodelan Sistem E-Learning".Paper. Institut Teknologi Bandung.

[2] Eko Wisnu. 2014. "Pengaruh Multipath Fading terhadap Performasi Pada Downlink Jaringan CDMA 2000 1X EV_DO Revision A". Paper. Universitas Brawijaya.

[3] Korinta Agita. 2013. "Analisis Perhitungan Fersnel Zone Wireless Local Area Network (WLAN) denganMenggunakan Simulator Radio Mobile".Paper. Universitas Sumatera Utara.

[4] Manurung Fenni. 2014. "Analisis Link Budget Untuk Koneksi Radio Wireless Local Area Networ (WLAN) 802.11b Dengan Menggunakan Simulasi Radio Mobile (Studi Kasus Pada Jalan Kartini Siantar - Ambarisan)". Paper. Universitas Sumatera Utara.

[5] Sujarit Indra. 2007. "Analisis sistem Jaringan Wifi dengan Jaringan GSM Indoor Pada Lantai Basement Balai Sidang Jakarta Convension Centre”. Paper. Universitas Trisakti. 
[6] Teddy Muhammad. 2009. "Rancang Bangun Antenna Eksternal Payung Bolik 2,4 GHz Untuk Komunikasi Wireless LAN". Jurnal Publikasi. Universitas Sumatera Utara Medan.

[7] Team Radio Mobile.Juni 2015. Tampilan antar muka software Radio Mobile. diakses pada di http://radiomobile.pe1mew.nl/. 